\title{
Proposes a Methodology AND ArChitecture Suitable For Generating the Process Plan of Machining Parts
}

\author{
RAHIMIC, S. \&VISEKRUNA, V.
}

Abstract: This paper proposes a methodology and architecture suitable for generating the process plan of machining parts. It is a proposal in which the peripheral processes needed for these parts are taken into account and they also enable the development of alternative process plans. The architecture supports the construction of CAPP systems from prepackaged, plug-compatible software components. The specifications of the architecture and its building blocks are defined. A prototype system is under development to prove the concept. This paper proposes a methodology and architecture suitable for generating the process plan of machining parts. It is a proposal in which the peripheral processes needed for these parts are taken into account and they also enable the development of alternative process plans.

Key words: methodology, architecture, CAPP system
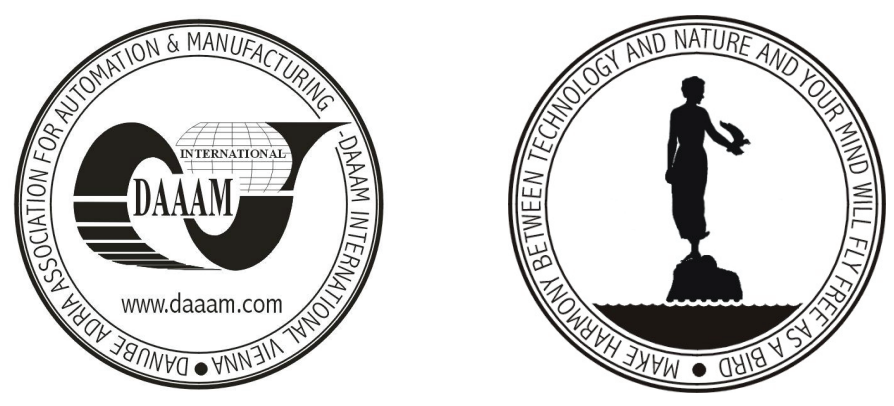

Authors' data: Mr. Sc. Rahimic S.[enad], Prof. Dr. Sc. Visekruna V.[ojo], Faculty of Mechanical engineering Mostar, Bosnia and Herzegovina, senad.rahimic@unmo.ba,vojo.visekruna@sve-mo.ba

This Publication has to be referred as: Rahimic, S. \&Visekruna, V. (2006). Proposes a Methodology and Architecture Suitable for Generating the Process Plan of Machining Parts, Chapter 41 in DAAAM International Scientific Book 2006, B. Katalinic (Ed.), Published by DAAAM International, ISBN 3-901509-47-X, ISSN 1726-9687, Vienna, Austria

DOI: $10.2507 /$ daaam.scibook.2006.41 